\title{
Mesoscale Numerical Study of Quasi-Stationary Convective System over Jeddah in November 2009
}

\author{
Mohammed Haggag ${ }^{1,2^{*}}$, Hesham El-Badry ${ }^{2,3}$ \\ ${ }^{1}$ Hydraulics and Irrigation Department, Cairo University, Cairo, Egypt \\ ${ }^{2}$ Resources and Environment Department, Dar Al-Handasah (Shair and Partners), Cairo, Egypt \\ ${ }^{3}$ Irrigation and Hydraulics Department, Ain Shams University, Cairo, Egypt \\ Email: *mohammed.abou-elhaggag@dargroup.com
}

Received July 18, 2012; revised August 20, 2012; accepted August 28, 2012

\begin{abstract}
25 November 2009 is an unforgettable day for the people in Jeddah, the second largest city in the Kingdom of Saudi Arabia (KSA). On that day, Jeddah turned into a disaster zone following a short heavy rainfall event that triggered flash floods leaving 122 fatalities and considerable losses. Numerical experiments using the Pennsylvania State UniversityNational Center for Atmospheric research mesoscale meteorological model (MM5) have been performed to investigate the event. It was caused by a short quasi-stationary mesoscale convective system that developed over Jeddah and lasted for about 8 hours. Rainfall totals computed by the model exceeded $400 \mathrm{~mm}$ in some localities in the southern part of Jeddah city and to the north of Jeddah in Thuwal city. The limited available observed rainfall totals, at King Abdul Aziz International Airport and wadiQaws rain gauges, and Jeddah's weather radar observations corroborates the ability of the model to reproduce the spatial and temporal characteristics of the rainfall event. A synoptic environment characterized by warm Red Sea surface temperatures and high humidity in the low levels of the troposphere. A stationary anticyclone centered over the southeast of the Arabian Peninsula concentrated the water vapour flow to a narrow passage over Jeddah. Simulation results suggested that the development of a mesolow by latent heat release, as well as cyclogenesis induced by Al Hejaz escarpments, could have played an important role in enhancing the event by providing low-level convergence and enhanced upslope winds, and upper level atmospheric instability.
\end{abstract}

Keywords: Jeddah Floods; MM5; Mesoscale; Cyclogenesis; Orography; Quasi-Stationary; Convection

\section{Introduction}

In less than fourteen months (from November 2009 to January 2011), the city of Jeddah in Kingdom of Saudi Arabia (KSA) went under water three times. The first was on 25 November 2009 when the city experienced its worst disaster in fifty years, 122 people were killed and 350 were reported missing. The second time was on December 30 in 2010 with 4 people killed. The last flash flood event took place in January 2011 leaving at least 11 people killed.

The topography of the western area of Arabian Peninsula (refer to Figure 1(a) for location) makes the region especially prone to flash-flood events. The mountain system adjacent to the coast of the Red Sea acts as a natural barrier to the warm moist Red Sea air, inducing the generation of intense rainfall rates with high spatial and temporal variability. Late autumn and winter bring relatively frequent convective events to the central part of the eastern Red Sea coast (Figure 1 for location). This

\footnotetext{
"Corresponding author.
}

stretch of the coast, the $\mathrm{Al}$ Hejaz region, is characterised by shallow coastal waters, a very narrow coastal plain and steep slope of the Mountains. Around Jeddah, the Al-Hejaz escarpment ridge rarely rises above $2100 \mathrm{~m}$, whilst the middle and southern portions (Asir escarpment and Al-Yemen escarpment) can reach heights over $3300 \mathrm{~m}$.

The western region of the Kingdom of Saudi Arabia (KSA) and especially the city of Jeddah $\left(21^{\circ} 30^{\prime} \mathrm{N}\right.$ $39^{\circ} 11^{\prime} \mathrm{E}$ ) (Figure 1) is frequently subject to heavy rainfall events that trigger hazardous flash floods. They mainly occur during late autumn and winter affecting a wide range of ephemeral stream systems (wadis) located in the area (Figure 1(b)). Jeddah is located along the coast of the Red Sea and it is the major urban center of the western KSA. It is the largest city in Makkah Province, the largest seaport at the Red Sea and the second largest city in KSA after the capital city (Riyadh). Figure 1 shows a recent high resolution multispectral satellite image of Jeddah city (GeoEye-1, $0.4 \mathrm{~m}$ resolution) that show the vertical and horizontal expansion of the city and the 

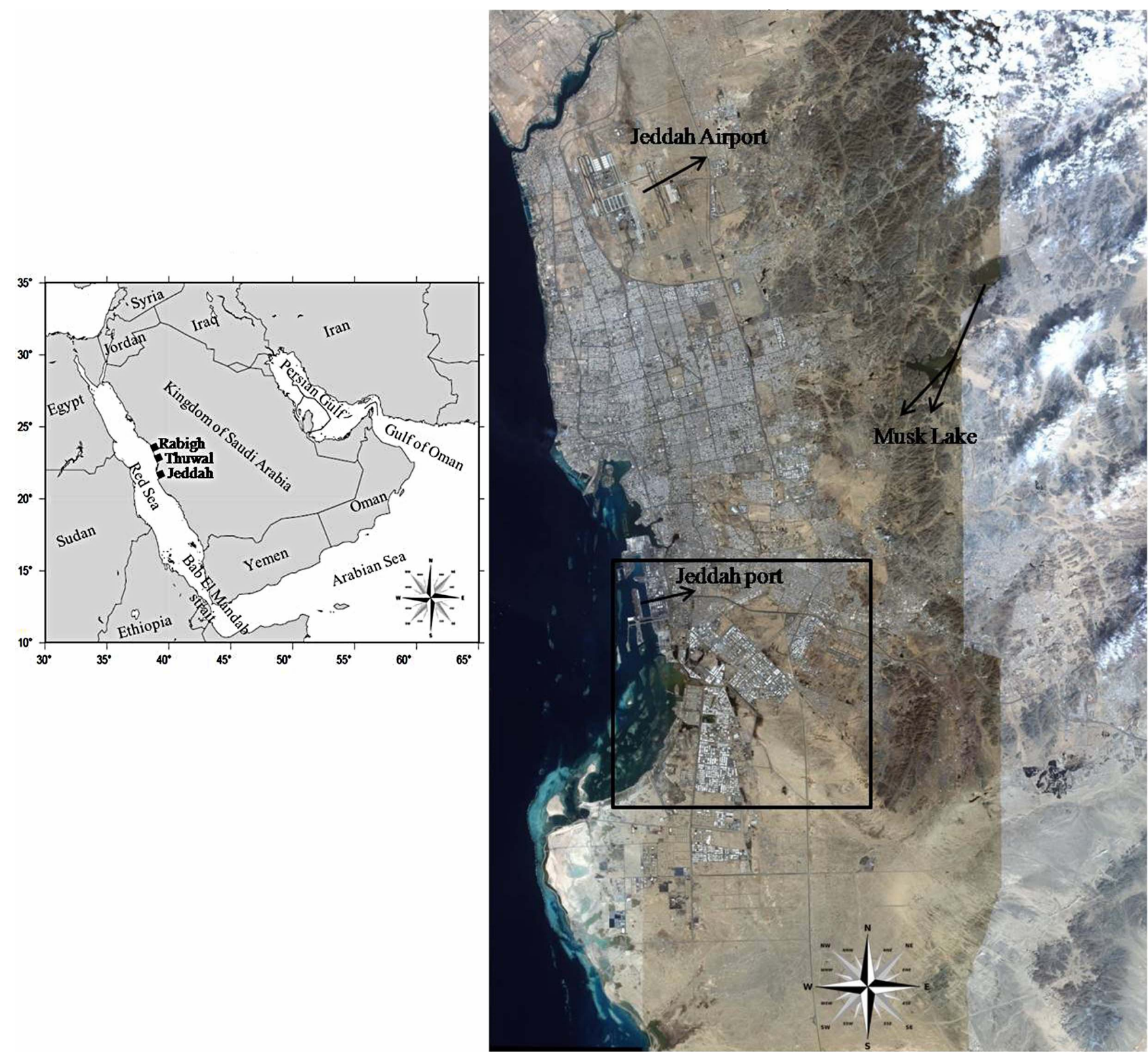

(a)

(b)

Figure 1. (a) The black filled rectangle indicates the location of main affected cities located in the western part of Saudi Arabia in the middle zone of the Red Sea (Jeddah, Thuwal and Rabigh). (b) A high resolution multispectral satellite image of Jeddah city (GeoEye-1, $0.4 \mathrm{~m}$ resolution) showing the vertical and horizontal expansion of the city and the mountains to the east. The area surrounded by the black rectangle is used for before and after flood comparison in Figure 2.

mountains to the east. Jeddah is the principal gateway to Makkah, the Islam's holiest city, which able-bodied Muslims are required to visit at least once in their lifetime and perform a pilgrimage.

In this paper, we consider the exceptional case of the quasi-stationary convective system over Jeddah on 25 November 2009. The system persisted for $8 \mathrm{~h}$, remaining nearly stationary during all the time over Jeddah. Accumulated rainfall observed in the northern part of the city, at Jeddah airport in $24 \mathrm{~h}$, exceeded $140 \mathrm{~mm}$, being higher than twice the annual mean rainfall rate in Jeddah $(\sim 50$ $\mathrm{mm} /$ year). The flash flood intensity was more severe in the southern and eastern parts of the city indicating higher rainfall intensities compared to that observed at Jeddah airport. The event produced one of the most catastrophic flash floods in the recent history of Jeddah. This paper is focused on the analysis of the storm event on 25 November 2009. The choice of November 2009 event was motivated by the amount of cumulated precipitation and the scale of resulting damages in the region.

Mesoscale numerical simulations are often used to identify the potential mesoscale mechanism that could 
explain the extraordinary stationarity and efficiency of the mesoscale system. In addition, the simulations are useful to explore the value of the mesoscale numerical models for operational forecasting of this type of events in the Arabian Peninsula region. It should be noted that, to date, despite of the frequent occurrence of similar storm events in the region (Jeddah) in the last few years, this paper would be the first investigation of the mesoscale mechanisms responsible for such kind of natural hazard events in the region.

Flash floods after short-intense rainfall events are one of the most frequent type dangerous natural hazard phenomena in the western KSA. In arid regions, flash floods form rapidly and flow down over watercourses that are initially dry. Flood occurrences are complex since they depend on geological and morphological characteristics of the catchments as well as on the meteo-hydrological phenomena such as rainfall, evaporation, groundwater storage and surface runoff [1]. In the western KSA, the interplay of typical cold-season synoptic conditions with orographic and thermal forcing produces significant convection along the coast and the mountain range. In this context, serious damage can occur when intense convective rainfall events combine with short hydrological response times, characteristics of steep streams and increasing urbanisation rates in coastal areas [2].

In the Arabian Peninsula region, the majority of literature dealing with hydrometeorological hazards is concerned with the hydrological investigation of the main watershed systems (e.g. runoff hydrograph, peak discharges, sediment flow). This kind of studies is useful as a basis for engineering studies related to flood protection, storm drainage and water resource management, e.g. [1,3, 4]. Previous work dealing with the numerical simulation of heavy rainfall events and its mechanisms of occurrence are very limited in the Arabian Peninsula region.

Many operational studies associated with precipitation forecasting are local or regional in scope. Some examples of international efforts in this field are [2,5-8]. [5] presented a forecasting approach of the potential for flash flood producing storms using the notion of basic ingredients. Storm ingredients that could be useful in forecasting are the rate of ascent of air, water vapour, precipitation efficiency, duration, speed of movement, size of the system and direction of the system movement. [5] described different meteorological processes by which these ingredients are combined to produce different types of heavy precipitation producing storms. [7] compared the results of applying seven meteorological models to the intense precipitation event occurred in southeastern part of France in September 2002. Two types of model were evaluated: 1) Operational models based on the hydrostatic assumption and 2) Research models based on the non-hydrostatic assumptions. Results from the non- hydrostatic models, based on higher horizontal spatial grid, were more representative to the observed rainfall fields compared to the results of the hydrostatic models. [6] carried out a study of two extreme rainfall events in eastern Spain over the Valencia region in November 1987 (with $800 \mathrm{~mm}$ rainfall in $24 \mathrm{~h}$ ) and in October 1982 (with $400 \mathrm{~mm}$ rainfall in $12 \mathrm{~h}$ ). The numerical analysis using the MM5 model indicated that both events were characterized by quasi-stationary MCS. In both cases, the MM5 model accurately predicted the spatial coverage as well as the duration of the mesoscale events; however, the model significantly underestimated the storm total precipitation. [2] investigated the feasibility of real time forecasting of flash floods over the Spanish Mediterranean area using the capabilities of the hydrological model forced by rainfall fields from a mesoscale atmospheric model. [2] focused on the flash flood event of June 2010 in the Llobregat basin in Catalonia region employing the Hydrologic Engineering Center's Hydrological Modelling System (HEC-HMS) and the MM5 model. The main finding of that study was the MM5 driven runoff simulation shows a reasonable reproduction of the observed discharge at the basin's outlet. MM5 proved to be a suitable tool for hydrometeorological forecasting of flash floods in Catalonia region.

Following this introduction, in the next section we present a brief discussion of the climate conditions in Jeddah and an overview of the synoptic environment that took place during the event. In Section 3, a description of the physical model characteristics and characteristics of the simulations are outlined. The simulation results of rainfall and its comparison with the available observations are presented in Section 4. Section 5 focuses on the mesoscale analysis relevant to the event. Finally, the paper is concluded in Section 6.

\section{The Study Area}

\subsection{Jeddah Climate}

The climate of Jeddah is of a hot arid desert type that is directly affected by the geographic location, which means high temperatures and humidity during the summer. These temperatures are around the $40^{\circ} \mathrm{C}$, when the city comes under the influence of a low pressure regime with dry and warm air masses. Humidity reaches its highest levels in summer because of the high temperature of seawater. [1] described the climate in Jeddah considering various air masses that affect the rainfall distribution over the area. The climatic condition in Jeddah in summer is a combination of Mediterranean cyclonic system, advecting from the north during winter, and a monsoonal system from the southeast. The orographic effects of the Al-Hejaz escarpment is the dominant factor that contro the quantity and pattern of rainfall around Jeddah. Long-term 
average annual rainfall rates observed over the Jeddah area from 1970 to 2005 indicates that the spatial variation of rainfall is influenced by the topography. The eastern parts of the catchments, located in the mountainous area, are receiving considerably more rainfall with an annual mean of more than $220 \mathrm{~mm} /$ year compared to the lower parts of the catchments, along the Red Sea coast, receiving an annual mean of less than $100 \mathrm{~mm} /$ year [1].

[9] based on ten years of weather records that cover the period between 1990 and 1999, showed that the temperature reaches a maximum of $49^{\circ} \mathrm{C}$ within the period between March and August, and a minimum of $17.3^{\circ} \mathrm{C}$ in the period between January and February. The relative humidity ranges between a maximum of $100 \%$ in the period between August to November, and a minimum of $5 \%$ in the period between January and March. The prevailing winds over Jeddah are northwest due to the city's coastal location on the shore of the Red Sea. These winds are usually light-to-moderate during most of the year. However, sometimes southerly winds blow throughout winter, spring and fall accompanied by a rise in temperature. These winds can sometimes become active and its speed may cause great sandstorms. They may also be accompanied by heavy rainfall. The most common type of rainfall is that due to thermal convection, which usually falls during the winter season as well as in the spring and fall due to the passage of low pressure from the west to the east and its confluence with the of Sudan's lowpressure regime over the region. Table 1 shows a statistical summary of the monthly average rainfall extracted from King Abdul Aziz International Airport weather station $\left(21.70^{\circ} \mathrm{N} 39.15^{\circ} \mathrm{E}\right)$.

Table 1. Average rainfall from King Abdul Aziz airport weather station (17 $\mathrm{m}$ above sea level) data derived from 292 months data between 1951 and 1983.

\begin{tabular}{cc}
\hline Month & Rainfall Rate $(\mathrm{mm})$ \\
\hline Jan. & 11.2 \\
Feb. & 4.5 \\
Mar. & 4.2 \\
Apr. & 1.0 \\
May & 0.9 \\
Jun. & 0.0 \\
Jul. & 0.1 \\
Aug. & 0.0 \\
Sep. & 0.1 \\
Oct. & 0.6 \\
Nov. & 18.2 \\
Dec. & 16.2 \\
Year & 56.1 \\
\hline
\end{tabular}

\subsection{The 25 November Storm Event}

On November 25, the first day of the 2009 Hajj pilgrimage season, in which 3 million pilgrims were gathering in the holy sites in and around Makkah, 80 kilometres to the east of Jeddah, unusual heavy rainfall occurred across the western parts of Saudi Arabia (Jeddah, Thuwal and Rabigh); the locations are shown in Figure 1. The rainfall event over Jeddah triggered severe flash floods that turned the city into a disaster zone. Some roads were under one metre of water on the second day, and many of the victims were believed to have drowned in their cars. At least 3000 vehicles were swept away or damaged with a considerable death toll. Rainfall gauges recorded a total of more than $180 \mathrm{~mm}$ in less than eight hours on $25 \mathrm{No}$ vember. This is nearly threefold the average of an entire year and the heaviest rainfall in KSA in a decade. The destruction due to the heavy rainfall and its associated flooding in Jeddah estimated at a billion Saudi riyals (US\$270 million). Figure 2 compares the conditions before and after conditions of the flash flood event in the area surrounded by the black rectangle given in Figure 1. The high resolution satellite images acquired by the GeoEye-1 of the southern part of Jeddah shows wide spread of vegetation (red filled circle and rectangle) and remaining stagnant water (small red stars) even a month after the event.

\subsection{Synoptic Description}

The quasi-stationary MCS formed over Jeddah was not a consequence of the Mediterranean depressions only as generally stated for most of the rainfall events in the area. The following analysis demonstrates that apart from the Mediterranean depression, there were at least three more characteristic weather conditions, which may provide favourable ingredients for the heavy rainfall event over Jeddah.

A stationary anticyclone was centered over the southeastern Arabian Peninsula and the Arabian Sea causing

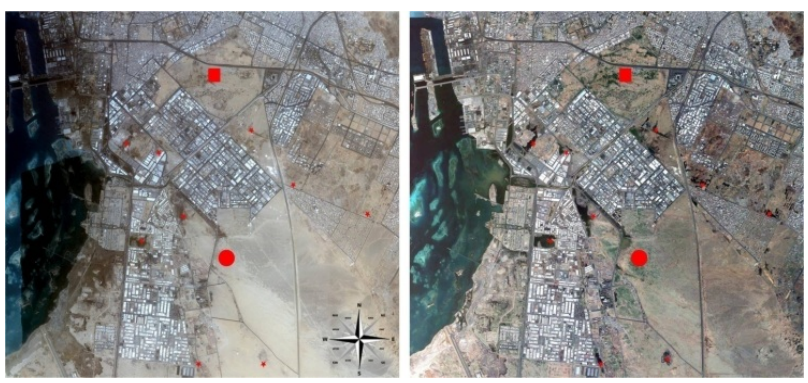

Figure 2. High resolution satellite images (GeoEye-1) of southern part in Jeddah (black rectangle in Figure 1) before the flash flood (left image) and afterward (right) taken 2 on January 2010 (more than 1 month after the event). After the event widespread vegetation (red filled circle and rectangle) and some stagnant water remained (small red stars). 
continuous clockwise flow over the Arabian and Red Seas and providing significant supply of moisture over the region. To the north of Jeddah, a Mediterranean cyclone was migrating from west to east combined with anticlockwise wind circulation. Figure 3 shows the geopotential height and wind field at $700 \mathrm{hPa}$ (based on NCEP-FNL reanalysis data) in addition to the Sea Surface Temperature (SST) (based on the Real Time Global SST analysis data) in the surrounding water bodies for three consecutive days $(24,25$ and 26 November in 2009). The anticyclone over the southeastern Arabian Peninsula kept a rather stationary position during this time period. The Mediterranean cyclone was migrating from west to east, at the early morning on 25 November (the onset of the rainfall event), the Mediterranean cyclone crossed the Red Sea and was centered over the Levant region, Figure 3(B). Theconcurrent existence of the migrating Mediterranean cyclone and the stationary Arabian Peninsula anti cyclone and the stationary Arabian Peninsula anticyclone caused a convergence zone to be formed along Jeddah's coast. At the early morning on November 26, the Mediterranean cyclone left the domain toward central Asia with the anticyclone still at its fixed position, Figure 3(C).

The warm Red Sea SST is another positive ingredient that enhanced the formation of the quasi-MCS. The apparent high SST fields in the Red Sea (304 K) compared to the Arabian Sea $(300 \mathrm{~K})$ can be explained by the limited mixing between the two water bodies that took place only through the Bab El-Mandeb strait, Figure 3. The existence of mountainous ranges surrounding the Red Sea basin from east and west is an additional factor that can lead to increase in its SST. According to a recent study of satellite-derived SST and ground-based air temperatures by [10], the waters of the Red Sea have warmed sharply by $0.7^{\circ} \mathrm{C}$ since 1994 , suggesting that the Red Sea is warming faster than the world average $\left(0.5^{\circ} \mathrm{C}\right)$ with climate change could be behind this rise. The warm seawater in the Arabian Sea and in the Red Sea produces significant amounts of water vapour increasing air humidity in the Red Sea basin. Deep moist convection in the area is enhanced due to the high moisture content and the buoyant instability that promotes strong upward vertical motion.

The combined effects of the above-mentioned factors (the stationary position of the Arabian Peninsula anticyclone, the Mediterranean cyclone, the warm seawater in the Arabian and Red seas, the high moisture content and the orographic effect of Al Hejaz escarpment) provided favourable conditions for quasi-stationary MCS to develop off the coast of Jeddah (the blue rectangle shown in Figure 3). The quasi-stationary MCS with its expected heavy precipitation rates along with the vulnerable catchment systems in Jeddah provided full set of ingredients

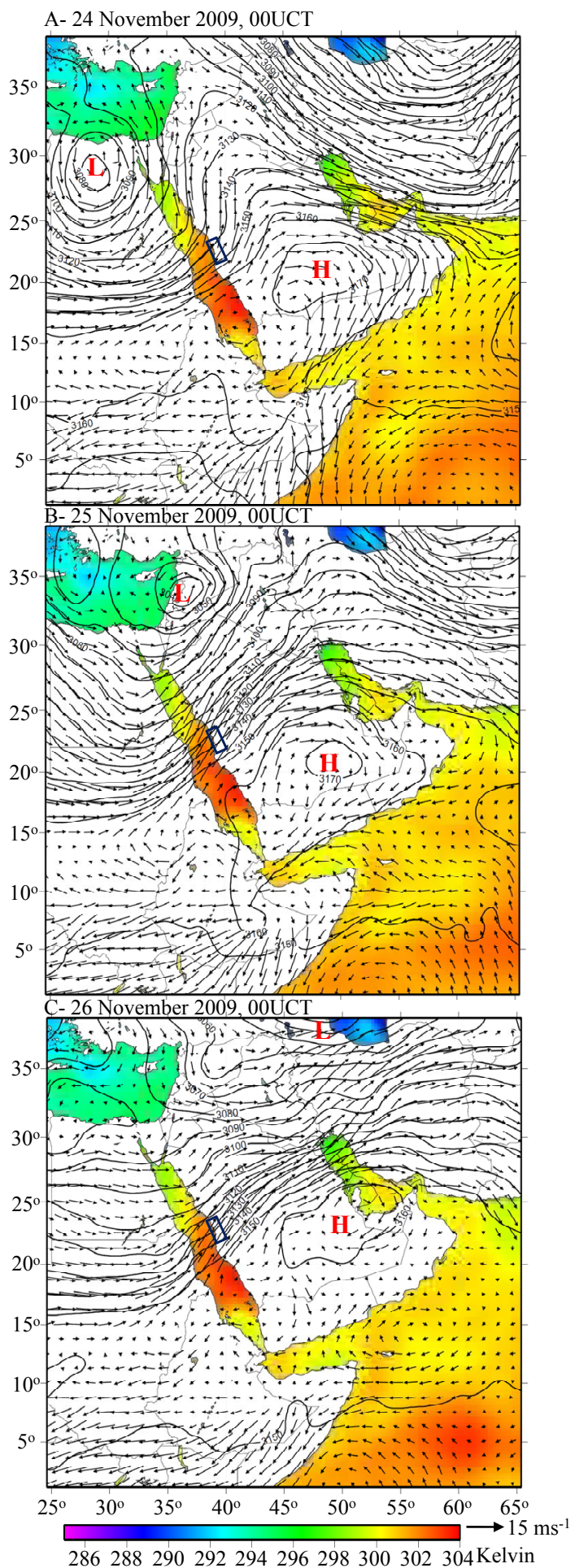

Figure 3. Synoptic conditions showing the 700 hPa geopotential height (contour lines), $700 \mathrm{hPa}$ wind vectors (arrows) and sea surface temperature (rainbow shading) over the Arabian Peninsula on 24 November 2009 (A), 25 November 2009 (B) and 26 November 2009 (C). H refers to the location of the stationary anticyclone over the southeastern Arabian Peninsula and $L$ refers to the migrating Mediterranean cyclone. The blue rectangle shows the area around Jeddah that is mostly affected by the rainfall event. 
for flash floods.

After the presentation of the synoptic environment during the event, the following sections will be devoted to a deeper investigation of the mesoscale event over Jeddah using numerical simulation.

\section{Model Description and Numerical Experiments}

Numerical simulation of the event was performed using fifth-generation mesoscale non-hydrostatic atmospheric model of the Pennsylvania State University-National Center of Atmospheric Research (PSU/NCAR, MM5 [11]; Hindcast simulation of the atmospheric circulation over the Arabian Peninsula was carried to study the different characteristics and mechanisms of the heavy rainfall event over Jeddah. The MM5 is formulated using the terrain-following sigma-coordinate system, with enhanced vertical resolution in the lower troposphere to represent adequately the boundary layer processes. A useful feature of the model is its multiple-nest capability, with two-way interaction between successive nesting levels that allows realistic terrain features. For the present simulations, four interacting domains (two-way nesting) were used, with $170 \times 170 \times 31,151 \times 151 \times 31,211 \times 211 \times$ $31,361 \times 361 \times 31$ grid points for the 1 st, 2 nd, 3 rd, and 4 th domain, respectively. All domains with its topography/bathymetry are shown in Figure 4. The coarse domain measures $4590 \mathrm{~km} \times 4590 \mathrm{~km}$ with a grid size of 27 $\mathrm{km}$ and centred over the central part of KSA. The second domain measures $1359 \mathrm{~km} \times 1359 \mathrm{~km}$ with a grid size of $9 \mathrm{~km}$ and centred over Jeddah. The third domain measures $633 \mathrm{~km} \times 633 \mathrm{~km}$ with a grid size of $3 \mathrm{~km}$ and centred over the same region. The finest domain is centred over Jeddah region, it measures $361 \mathrm{~km} \times 361 \mathrm{~km}$ under a Mercator map projection (horizontal grid spacing is 1 $\mathrm{km})$.

Global Geological Survey (USGS) elevation data, USGS global 25-category land use data, global 17 category soil data are used to represent elevation, land use, soil, respectively. Initial and boundary conditions for the coarse grid are constructed from the large-scale analysis data from NCEP at NCAR from 24 November 00.00 UTC to 26 November 00.00 UTC. The NCEP Final Analysis (FNL) data archived at NCAR exists every 6 hours at a spatial resolution of $1^{\circ} \times 1^{\circ}$ at 21 standard pressure levels under $100 \mathrm{hPa}$. The data includes two-dimensional variables including SST, sea level pressure and threedimensional variables of temperature, geopotential height, $\mathrm{U}$ and $\mathrm{V}$ components and relative humidity. The resulting fields are interpolated to the model levels and the initialization process is completed with interpolation of the coarse grid fields to the fine grid. Real Time Global SST analysis data (RTG SST) available at horizontal resolution of $0.5^{\circ} \times 0.5^{\circ}[12]$ was used to represent the SST in the surrounding water bodies.

The simulation extended for $48 \mathrm{~h}$, started at $0000 \mathrm{UTC}$

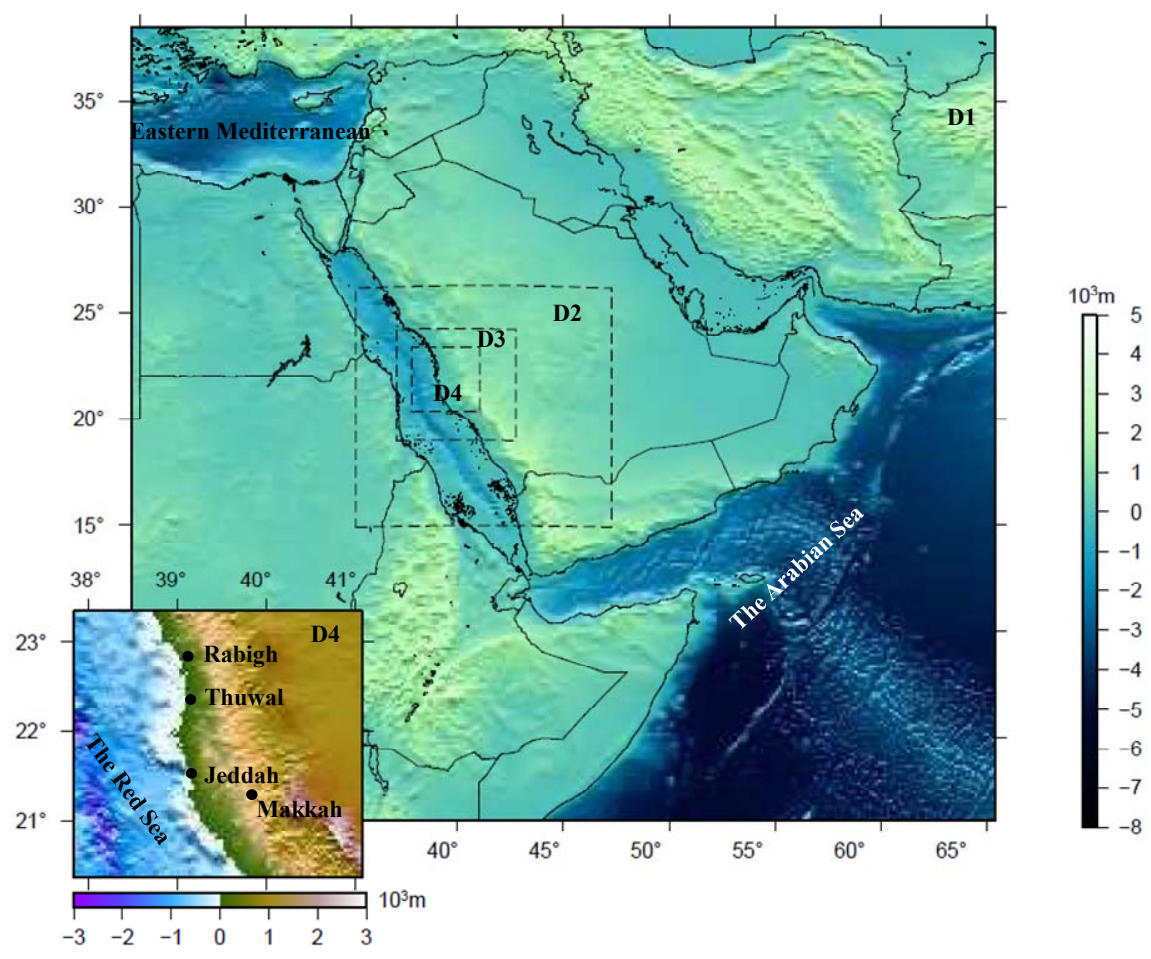

Figure 4. Depiction of the bathymetry/topography of the four simulation domains over the Arabian Peninsula. The data used in the plot is the GEBCO_08 global bathymetric grid at 30 arc-seconds. 
on 24 November 2009. NCEP-FNL global analyses are available at 0000, 0600, 1200 and 1200 UTC. The tendencies along the model coarse domain boundaries, specified by differences of the fields between those times, were applied using a Newtonian relaxation approach [11]. The model incorporated many options for the physical parameterizations. In the present study, the parameterizetion scheme used to represent the Planetary Boundary Layer (PBL) physics was the Hong-Pan PBL scheme [13]. Surface temperature over land was calculated using the Five-Layer Soil model model [14], and over sea was kept constant during the simulation. Surface fluxes, as well as atmospheric temperature tendencies caused by longwave and shortwave radiation components, were calculated using the cloud-radiation scheme [15]. Explicit microphysics was represented with Mixed-Phase (Reisner 1) that includes the effects of hydrostatic water loading, condensation, evaporation, melting, freezing, deposition, and sublimation and super cooled liquid water [16]. The Grell parameterization scheme [11] was selected to calculate moist convection effects on the coarse grid domains (domains 1 and 2), whereas no cumulus parameterization was adopted for the fine grid domains (domains 3 and 4).

\section{Rainfall Simulation}

The study area is characterized with scarcity in available meteorological observations needed to prove or disprove modelling studies. Accumulated rainfall depth at only two rain gauges located in the study area was acquired for the comparison with modelling results. Table 2 shows a comparison between the observed and the computed accumulated rainfall rates at King Abdul Aziz International Airport (KAIA) and wadiQaws rainfall gauges, located in Jeddah. The accumulated rainfall at the rain gauges from 24-26 November in 2009 was 140.2 and $180.0 \mathrm{~mm}$ at KAIA and wadiQaws, respectively. The corresponding simulated values at the two locations were 130.71 and $170.9 \mathrm{~mm}$. The rainfall depth at KAIA accumulated over $8 \mathrm{~h}$ with maximum hourly rate of about $84.7 \mathrm{~mm} / \mathrm{h}$. At wadiQaws, the peak rainfall intensity came $2 \mathrm{~h}$ later with a peak value of $66.6 \mathrm{~mm} / \mathrm{h}$. This limited comparison reveals that the simulated rainfall field reproduced the spatial and temporal characteristics of the stationarity of the MCS over the area. Comparing the simulated rainfall with the estimated rainfall field form Tropical Rainfall Measuring Mission (TRMM 3B42) at the rain gauges shows significant underestimation of the event. The accumulated rainfall depth at the two rain gauges, as estimated by TRMM, from 24-26 November in 2009, was 34.91 and $60.98 \mathrm{~mm}$ at KAIA and wadiQaws, respectively. These values represented one third of the observed rainfall, Table 2.

TRMM's underestimation of this event is apparent
Table 2. Comparison of observed and computed accumulated rainfall depth at rain gauge sites with acquired observations.

\begin{tabular}{cccccc}
\hline & Lon. & Lat. & Obs, & Comp. & TRMM \\
\cline { 2 - 6 } Jeddah & 39.15 & 21.70 & $\mathbf{1 4 0 . 2 0}$ & $\mathbf{1 3 0 . 7 1}$ & 34.11 \\
$\begin{array}{c}\text { KAIA) } \\
\text { Wadi }\end{array}$ & 39.36 & 21.50 & $\mathbf{1 8 0 . 0 0}$ & $\mathbf{1 7 0 . 9 4}$ & 60.98 \\
$\begin{array}{c}\text { Qaws } \\
\text { Southern }\end{array}$ & 39.36 & 21.32 & NA & 432.20 & 76.95 \\
$\begin{array}{c}\text { Jeddah } \\
\text { KAUST- } \\
\text { Thuwal }\end{array}$ & 39.39 & 22.20 & NA & 410.50 & 82.13 \\
\hline
\end{tabular}

from Figure 5 that shows the spatial distribution of the accumulated rainfall (computed by MM5, and estimated by TRMM) in domain-3 from 24-26 November. The simulation results reflect the high stationarity of the main MCS as clearly reflected in the presence of the system over the coastal area of Jeddah and Thuwal with 8-h rainfall1 exceeding $400 \mathrm{~mm}$ (Figure 5(A)).

Embedded within this MCS, there are two rainfall maxima of about $400 \mathrm{~mm}$, one over the southern part of Jeddah and the other one (main) is located over Thuwal to the north of Jeddah. TRMM's rainfall shows the location of these rainfall maxima but with significant underestimation of the accumulated rainfall depth (Figure 5(B)). TRMM showed a maximum accumulated rainfall over the domain of about $100 \mathrm{~mm}$.

It has been proved by several sources that TRMM significantly underestimates rainfall events, especially in case of complex terrain conditions. [17] showed that TRMM-3B42 underestimates both the occurrence and amount of rainfall over mountainous areas. This was attributed partly to orographic warm rain process over the mountains. [18] explained the rainfall underestimation by TRMM-3B42 during the monsoon period over Bangladesh by the vertical cross section of convection obtained by TRMM-PR 2A25 data. [19] showed that TRMM data considerably underestimated rainfall during the peak monsoon months in Indian west coast. [20] showed about $30 \%$ underestimation of TRMM during warm seasons over China by comparing rainfall amount from a rain gauge network and TRMM data. In this study, it was unfortunate that scarcity of rainfall observations at ground rain gauges limited our ability to judge the accuracy of the computations. A wider look at the computed rainfall in the coarse domain shows that rainy events took place only over Jeddah region and another region over the Arabian Sea (not shown); this limited the possibility to verify the modelling results using rainfall data from other rain gauges located in the coarse domain.

The severity of the MCS can be revealed on the rainfall radar image (Figure 6(B), source: Presidency of Meteorology and Environment, Saudi Arabia) that shows the 

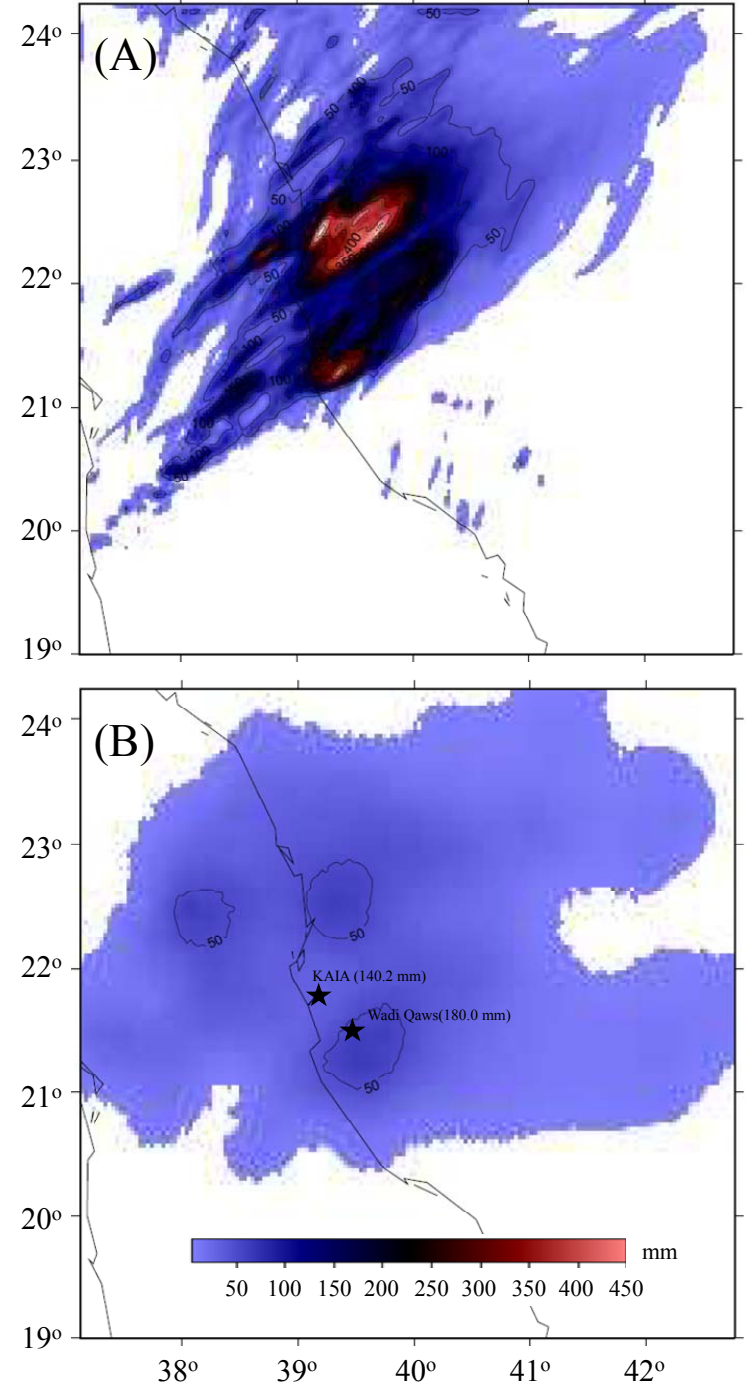

Figure 5. Comparison of computed (domain 3) and TRMM's accumulated rainfall from 24-26 November in 2009 over western Saudi Arabia. The black stars in (B) show the location of KAIA and wadiQaws rain gauges along with the recorded rainfall depth.

1-hour accumulation of radar-measured rainfall rates over Jeddah region at 1900 UTC on 25 November. The rainfall maximum over southern Jeddah was about $80 \mathrm{~mm} / \mathrm{h}$ with a minimal rainfall activity at northern Jeddah. This compares quite well with the simulated rainfall intensity (Figure 6(A)) that shows adequate performance of the model in reproducing the spatial and temporal extents of the MCS. Keeping in mind that the majority of the flash flood hazards were confined in the southern part of Jeddah, this proves the adequacy of the modelling results in simulating the event.

The rainfall distribution as computed over the region was not uniform (Figure 5(A)), the rainfall variability in the study area is high; ranging from less than $50 \mathrm{~mm}$ to the north east of Jeddah to about $400 \mathrm{~mm}$ over Thuwal
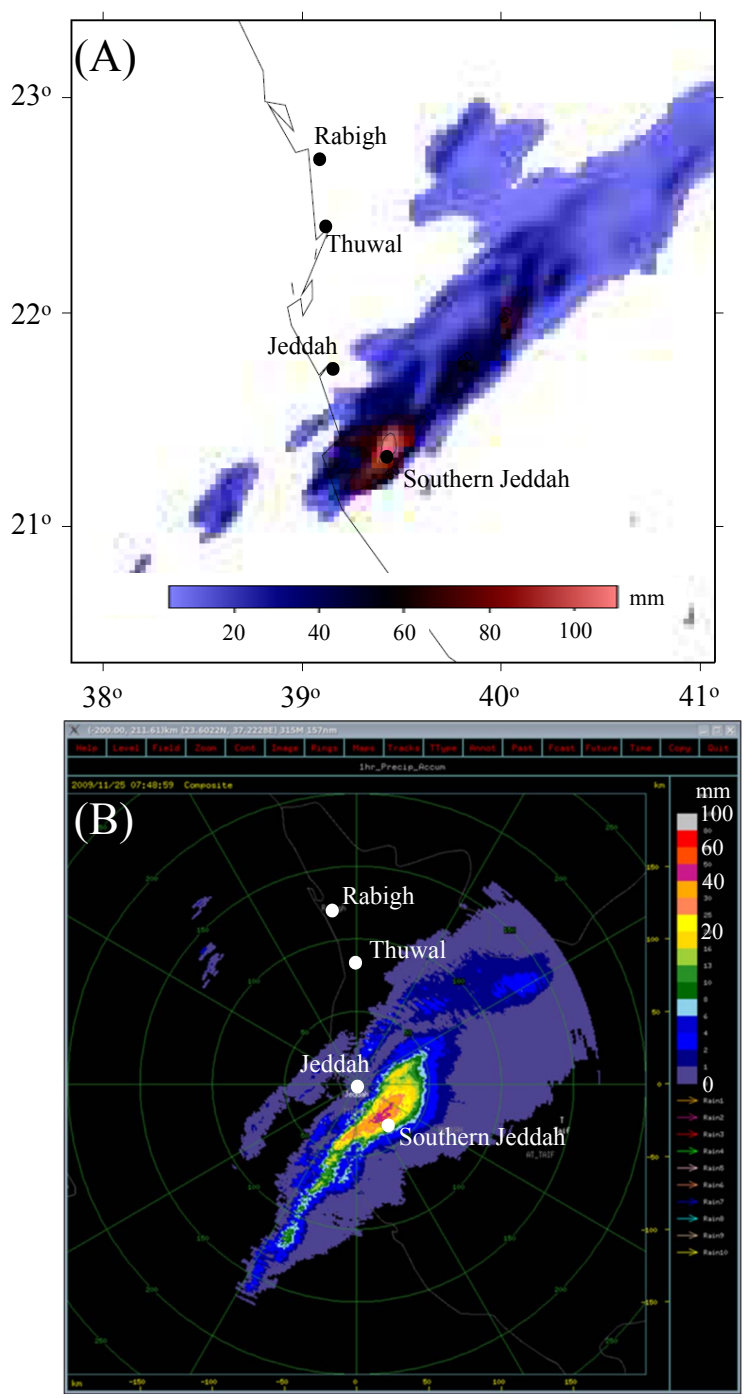

Figure 6. (A) Hourly rainfall intensity computed by MM5 (domain 4) versus (B) Jeddah's rainfall radar observations at 1900 UTC on 25 November 2009. Both show rainfall maxima over southern Jeddah in the order of $80 \mathrm{~mm} / \mathrm{h}$.

and Southern Jeddah. Most of Jeddah have received a rainfall total of $100-200 \mathrm{~mm}$. There were many factors affecting the rainfall distribution irregularity, such as the topographic configuration, the wind direction and the magnitude and locality of thermal convection. The existence of the Al-Hejaz escarpment along the Red Sea coast, approximately 70 to $100 \mathrm{~km}$ inland with a steep western slope and rather milder eastern slope was a dominant factor in the local rainfall distribution.

The accumulated and hourly rainfall rates, in the period from 24-26 November in 2009, at four stations nearby Jeddah are shown in Figure 7. Names and coordinates of these four locations are given in Table 2. The KAIA and wadiQaws rain gauges coincide with real weather stations operated by the KSA government, Southern Jeddah and Thuwal rain gauges are hypothetical stations 

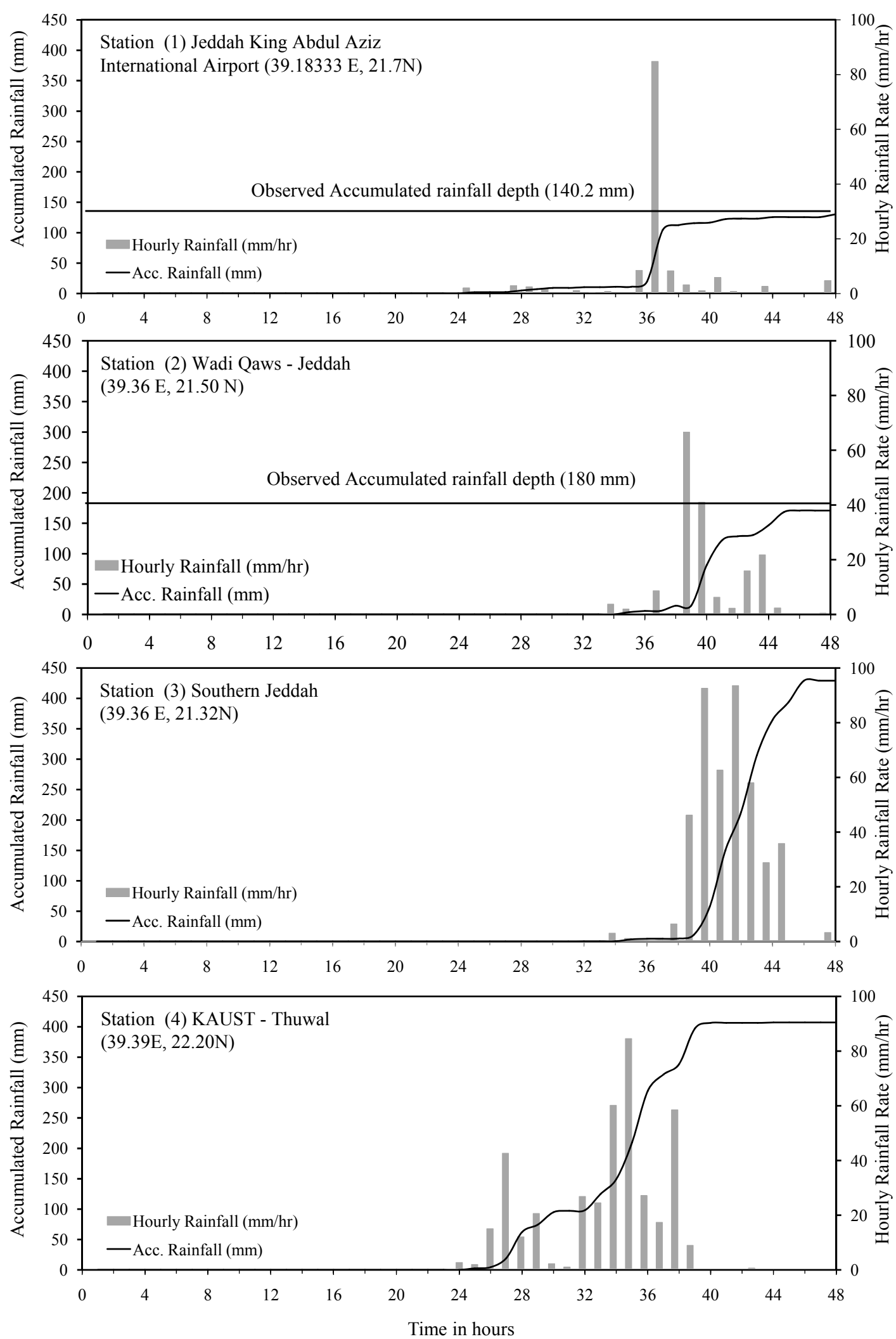

Figure 7. Time series of accumulated and hourly rainfall rates at several locations near Jeddah from November 2400 UTC to November 2600 UTC in 2009. The gray bars represent the computed hourly rainfall (from domain 4) and the black solid line is the accumulated rainfall depth. The solid line shows the observed accumulated rainfall at KAIA and wadiQaws rain gauges. 
selected to present the rainfall maxima in the MCS. The total computed accumulated rainfall depth at KAIA was $130.71 \mathrm{~mm}$ with a peak hourly rainfall rate of $84.7 \mathrm{~mm} / \mathrm{h}$ while the observed accumulated rainfall depth was 140.2 $\mathrm{mm}$. At wadiQaws, the total computed accumulated rainfall depth was $170.9 \mathrm{~mm}$ with a peak hourly rainfall rate of $66.6 \mathrm{~mm} / \mathrm{h}$ while the observed accumulated rainfall depth was $180 \mathrm{~mm}$. The maximum computed rainfall intensity in Southern Jeddah was $93.5 \mathrm{~mm} / \mathrm{h}$ with an accumulated depth of $432.2 \mathrm{~mm}$ (no observations available). In Thuwal to the north of Jeddah, the maximum computed rainfall intensity was $84.5 \mathrm{~mm} / \mathrm{h}$ with accumulated depth of $410.5 \mathrm{~mm}$ (no observations available). Figure 7 shows that the MCS was centered over the northern part of the domain (Thuwal) in the early morning of November 25 lasting for $12 \mathrm{~h}$, later on a small mesoscale cell affected the southern part of Jeddah in the afternoon of November 25 for just $4 \mathrm{~h}$.

Fortunately, most of the areas covered with the maxima of the MCS are not inhabited with large population densities. According to the local media news, the southern part of Jeddah was badly affected with most of the 122 causalities reported over there. This provides another evidence of the reasonability of the modelling results of the event.

\section{Mesoscale Ingredients}

The previous section showed that the MM5 model was able to reproduce quite accurately the location and intensity of the heavy precipitation event over Jeddah (Figures 5(A), 6 and 7). The model provided good indications about the stationary position and short living time of the convective system that developed over Jeddah. Model's ability in capturing the location, short interval of the precipitation system seems to be associated with the satisfactory prediction of the large-scale aspects of the circulation as embedded in the reanalysis data used for initial and lateral boundary conditions. However, the spatial localization and high precipitation efficiency of the system have to be related to the mesoscale ingredients. Definitely, the circulation pattern in the lower troposphere is rich in mesoscale components that can reasonably explain the convective development over Jeddah.

First, the mesolow area situated to the north west of the Al Hejaz escarpment was contributing with an increase of southwesterly and northwesterly flow over Jeddah as it increased the pressure gradient, Figure 8. Simulation showed that this low is started to the north of Jeddah (Thuwal) in the early morning of 25 November and then migrated to the south and situated over southern Jeddah in the afternoon of the day (not shown). The maintenance of the mesolow over a small geographical domain probably could be explained by the constant in-

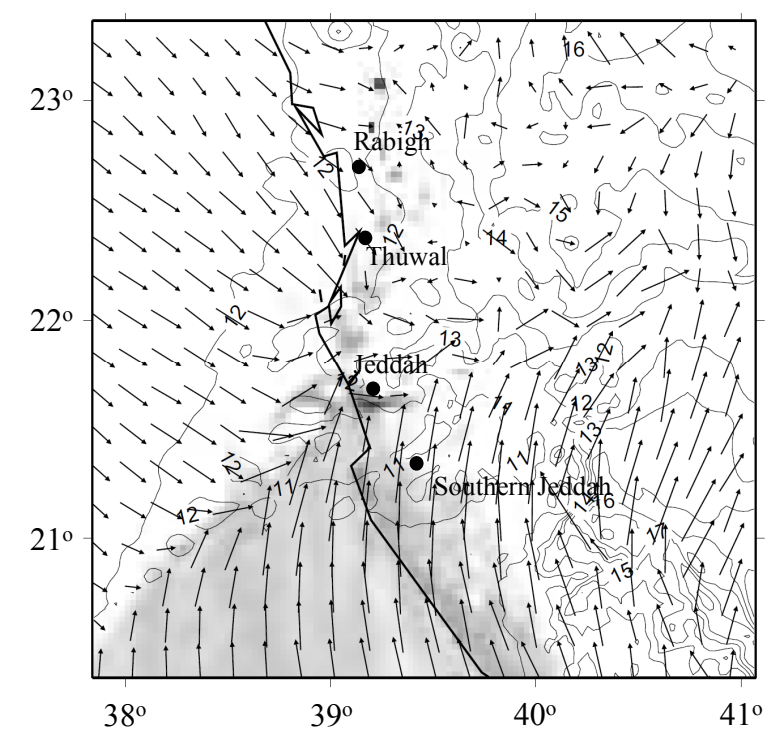

Figure 8. Model simulated surface fields (domain 4) valid at 1500 UTC in 25 November, sea level pressure (contour lines with interval $1 \mathrm{hPa}$ ), horizontal surface wind vectors converging near the mesolow over Jeddah and surface mixing ratio $(\mathrm{g} / \mathrm{kg})$ with shaded area of mixing ratios greater than 8 g/kg.

teraction of the upper-level flow with the Al-Hejaz orography. The mesolow center was always coincident with where the heaviest rainfall occurred, Figure 8. The mesolow genesis was concurrent with the onset of the rainfall over Thuwal. Subsequently, it moved to the south approximately in phase with the maximum rainfall, as new troughs developed over Jeddah in response to new precipitation. The succession of events suggested that this low could be a result of intense latent heat release in the atmospheric column over Jeddah. A strong low-level convergence associated with the low helped to maintain and enhance the condensation and the precipitation over the area. The mesolow acted on intensifying and concentrating the low level wind field (northwesterly and southwesterly components), producing an intense low-level convergence zone over Jeddah, Figure 8.

Figure 9 shows high values of vertical moisture flux convergence, calculated as the difference between the mixing ratio $(\mathrm{q}, \mathrm{g} / \mathrm{kg})$ times the vertical wind component $\left(\mathrm{w}, \mathrm{ms}^{-1}\right)$ in the vertical model levels and the lower troposphere over the affected area. The moisture flux convergence was useful in the prediction of flash flood conditions since it parameterized two important ingredients for deep, moist convection: upward motion in the presence of low-level moisture [5,6]. Calculation of potential or convective instability between 1000 and $700 \mathrm{hPa}$ (solid contours in the same figure) revealed the presence of strong instability over the western part of KSA. The most western part of this region of unstable stratification combined high values of low-level moisture (shaded area 


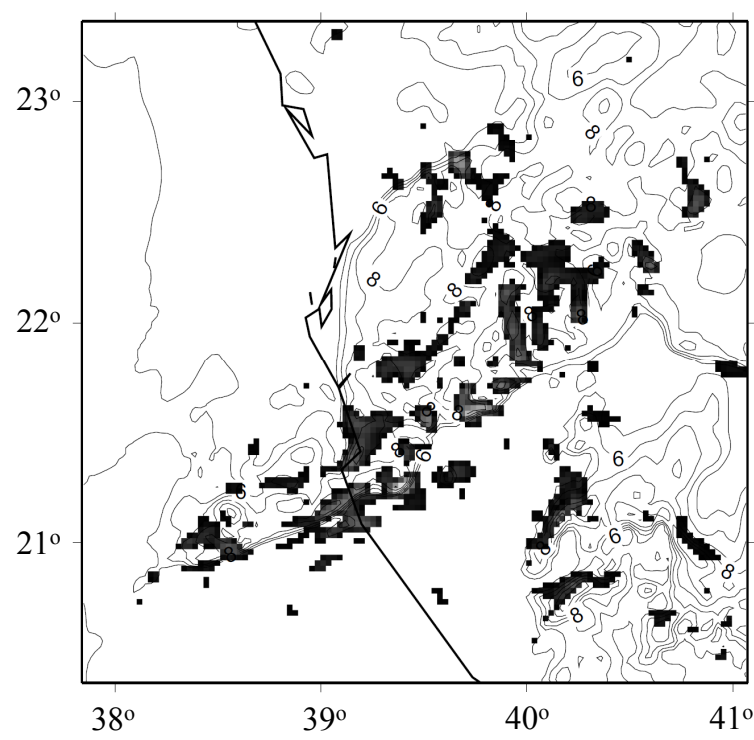

Figure 9. Convective instability represented as the potential temperature difference between 1000 and $700 \mathrm{hPa}$ (contour lines at intervals of $2 \mathrm{~K}$ ) and vertical moisture flux convergence in the $1000-700 \mathrm{hPa}$ (shaded with values greater than $10 \mathrm{~g} \cdot \mathrm{kg}^{-1} \cdot \mathrm{m} \cdot \mathrm{sec}^{-1}$ ), valid at 1500 UTC in 25 November.

in Figure 10), whereas the northeastern and southeastern parts were characterized by drier air, advected from direr origins. The precipitation distribution (Figure 5) was nearly following the spatial distribution of the atmospheric instability and moisture convergence as depicted in Figures 8 and 9.

The geographical location of Jeddah along the northwest end of the Al Hejaz escarpment was an additional factor leading to the formation of efficient mesoscale systems that trigger flash floods. On 25 November event, the efficiency of the MCS was seen partially related to the cyclogenesis in Al Hejaz escarpment. Warm moist air masses originated above the warm Red Sea water were forced to rise in the atmosphere because of the orography (2400 $\mathrm{m}$ in some parts). Figure 10(A) shows a typical profile of the topography in the southwestern KSA. A longitudinal profile from $38^{\circ} \mathrm{E}$ to $43^{\circ} \mathrm{E}$ at latitude $20.75^{\circ} \mathrm{N}$ shows levels of more than $2400 \mathrm{~m}$ with a steep slope to the west and rather mild slope to the east. As the warm moist air masses were forced to climb the mountains, latent heat was continuously released resulting in reduction in the stable temperature gradient in upper atmospheric levels. This resulted in the formation of a pressure ridge above the mountains above $2000 \mathrm{~m}$. Figures 10(B)-(D)) shows profiles of computed geopotential heights at 600,550 and $500 \mathrm{hPa}$, respectively. A pressure gradient formed in the vertical separating between highpressure zone above the mountains and low-pressure zone below in the west side of the mountains over the Red Sea and the coastal plains. The pressure gradient might create a convergence zone to the west of the mountains and a divergence zone to the east. The low pressure zone northwest of Al Hejaz escarpment (Situated over Jeddah), resulted in the formation of a cyclonal vortex that support the thermal convection and hence enhancing the condensation and further release of latent heat. This kind of local atmospheric circulation might enhance the efficiency of the MCS and trigger heavy quasi-stationary rainfall with short time interval causing flash floods.

\section{Conclusions}

This paper presented a mesoscale numerical study of November 25 in 2009 exceptional heavy rainfall event that triggered catastrophic flash floods in Jeddah city, Saudi Arabia. Special emphasis on the aspects of synoptic and mesoscale ingredients that could explain the reasons for the stationarity and the high efficiency of the mesoscale event were presented. Jeddah city turned into a disaster zone following the flash flood of that day leaving 122 causalities and enormous losses in properties and infrastructure. The Penn. State Univ., National Center for Atmospheric Research mesoscale atmosphere model (MM5) was used to investigate the extreme precipitation over Jeddah.

The analysis indicated the presence of some synoptic scale features that occurred concurrently leading to enhancing the severity of the event. The above average warming of seawater in the Red Sea associated with strong warm-moist air masses penetrating from the Arabian Sea toward the Red Sea provided ideal fuel source for thermal convection in the escarpments surrounding Jeddah. A low-pressure zone formed off the coast of Jeddah by joining a migrating Mediterranean low-pressure and an extension of Sudan low-pressure zone. A stationary anticyclone centered over the southeast of Arabian Peninsula concentrated the water vapour movement to a narrow passage through Jeddah.

The simulations showed accumulated rainfall depth maxima in excess of $400 \mathrm{~mm}$ in less than 12 hours over a region with rainfall annual mean of $\sim 50 \mathrm{~mm} / \mathrm{yr}$. Lack of rainfall observations from ground stations in the region was a fact that put limitation on proving or disproving the simulation results. The authors did their best to acquire rainfall observations during the event, the two available records from King Abdul Aziz International Airport and wadiQaws rain gauges showed excellent performance of the model in reproducing the heavy rainfall over Jeddah and emphasized the significant underestimation in the rainfall filed estimated by the Tropical Rainfall measuring Mission (TRMM). Another evidence was provided from an image acquired from Jeddah rainfall radar, it proved the model capability in reproducing the spatial and temporal distribution of the heavy rainfall 

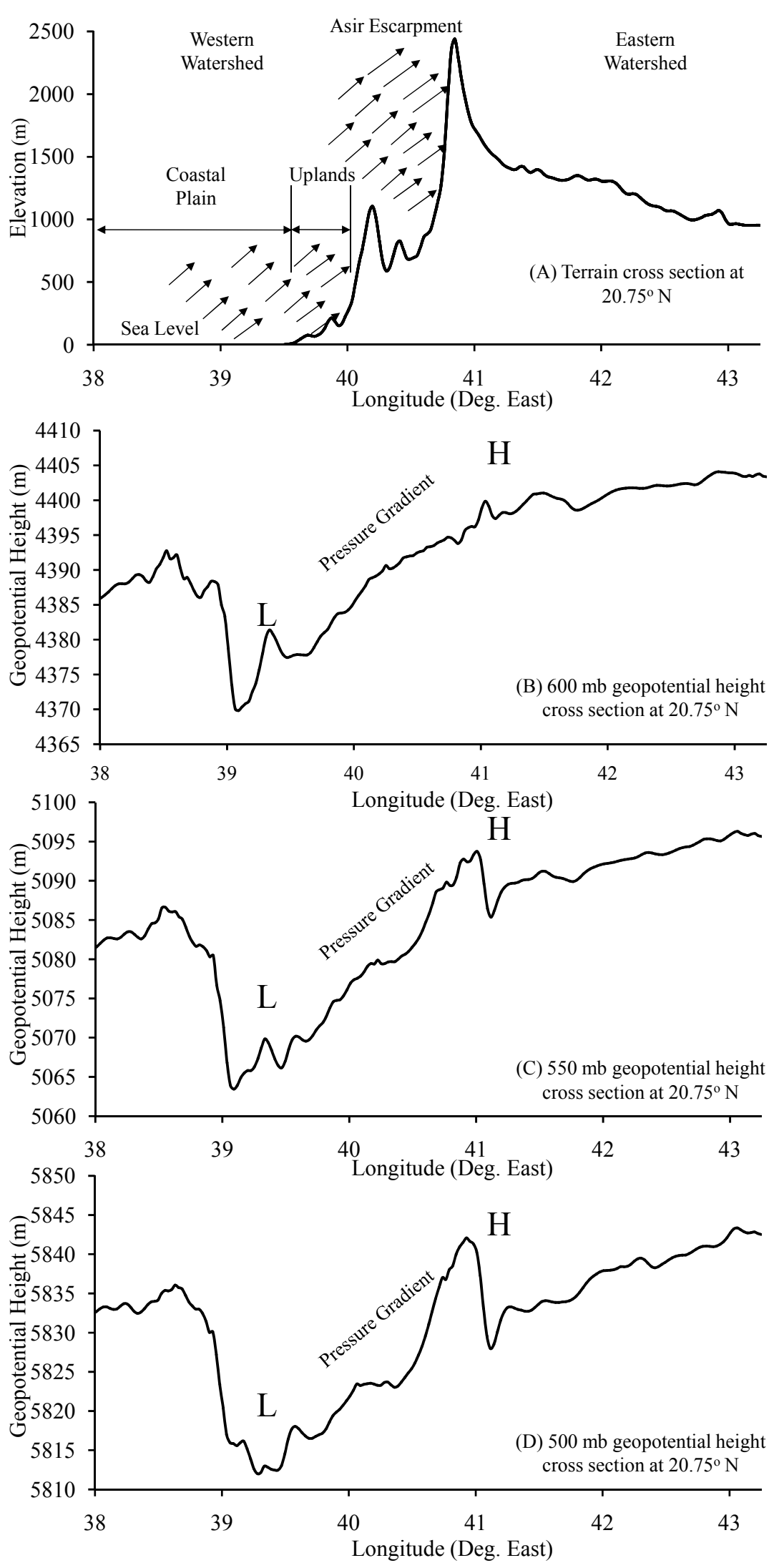

Figure 10. (A) Typical profile of the topography in the southwestern Saudi Arabia. (B)-(D) Cross sections of computed geopotential heights (domain 3) at 600, 550 and $500 \mathrm{mb}$, respectively. 
over the area. The aftermath losses of the flash flood in Jeddah provided another evidence; most of the losses were confined to the southern part of the city where the simulation results produced accumulated rainfall depth of more than $400 \mathrm{~mm}$. The rainfall maxima to the north of Jeddah over Thuwal, fortunately, did not trigger many casualties as it took place over an uninhabited area. The campus of King Abdullah University of Science and Technology in Thuwal was severely affected by the event.

The complex topography of the western Saudi Arabia facilitated the association of most of the flash floods in the area with MCSs triggered or sustained by coastal orographic lifting and associated cyclogenesis in the $\mathrm{Al}$ Hejaz escarpment. A mesolow was centered and sustained over Jeddah because of cyclogenesis and latent heat release from moist-warm air forces to rise in the troposphere by the orographic effects. The mesolow caused sustained channelized surface wind convergence over Jeddah enhanced by the blocking effect of the surrounding high-pressure centers. The combined effect of these factors resulted in atmospheric instability fuelled with warm-moisture causing unusual rainfall event over the area.

Even though not discussed thoroughly in the paper, it should be noted that frequent flooding events in the western parts of Saudi Arabia in the last decade (especially in Jeddah) motivated several researchers to investtigate the impacts of climate change on the hydrological cycle in the region [21-24]. Predicted future climate change impacts for western Saudi Arabia include higher temperatures and increase in precipitation, therefore leading to intensification of the hydrologic cycle. One of the expected consequences of change is increase in the magnitude and frequency of extreme events (high intensity rainfall, flash flooding). This increase is mainly related to the influence of the Inter-Tropical Convergence Zone in summer and autumn, as its northernmost extent moves further north throughout the century and to the expected warming in the surrounding water bodies (Arabian Sea, Red Sea). These factors along with the complex terrain conditions and widespread urbanization downstream of ephemeral streams suggest that, in the future, Jeddah area is prone to severe flash flood events similar to the 25 November event, or even worse.

\section{Acknowledgements}

This work was performed while the first author held a visiting associate-professorship at Hiroshima University provided by the Global Leaders Environment Program (GEL). The discussion and suggestions provided by Prof. Jos Lelieveld from the Cyprus Institute are greatly acknowledged. Acknowledgment is due Dar Al-Handasah, a leading multi-disciplinary consultant firm in the Middle
East, for providing data \& logistics needed to accomplish the paper.

\section{REFERENCES}

[1] A. M. Subyani, "Hydrologic Behavior and Flood Probability for Selected Arid Basins in Makkah area, Western Saudi Arabia," Arabian Journal of Geosciences, Vol. 4, No. 5-6, 2009, pp. 817-824. doi:10.1007/s12517-009-0098-1

[2] A. Amengual, R. Romero, M. Gomez, et al., "A Hydrometeorological Modeling Study of a Flash-Flood Event over Catalonia, Spain," Journal of Hydrometeor, Vol. 8, No. 3, 2007, pp. 282-303.

[3] A. M. Subyani, "Geostatistical Study of Annual and Seasonal Mean Rainfall Patterns in Southwest Saudi Arabia," Hydrological Sciences, Vol. 49, No. 5, 2004, pp. 803817.

[4] M. A. Nouh, "Wadi Flow in the Arabian Gulf States," Hydrological Processes, Vol. 20, No. 11, 2006, pp. 23932413.

[5] C. A. Doswell, H. E. Brooks and R. A. Maddox, "Flash Flood Forecasting: An Ingredients-Based Methodology," Weather and Forecasting, Vol. 11, No. 4, 1996, pp. 560581.

[6] R. Romero, C. A. Doswell and C. Ramis, "Mesoscale Numerical Study of Two Cases of Long-Lived Quasi-Stationary Convective Systems over Eastern Spain," Monthly Weather Review, Vol. 128, No. 11, 2000, pp. 3731-3751.

[7] S. Anquetin, E. Yates, V. Ducrocq, et al., "The 8 and 9 September 2002 Flash Flood Event in France: A Model Intercomparison," Natural Hazards and Earth System Sciences, Vol. 5, No. 5, 2005, pp. 741-754. doi:10.5194/nhess-5-741-2005

[8] A. Amengual, R. Romero, M. Vich and S. Alonso, "Inclusion of Potential Vorticity Uncertainties into a Hydrometeorological Forecasting Chain: Application to a Medium Size Basin of Mediterranean Spain," Hydrology and Earth System Sciences, Vol. 13, No. 6, 2009, pp. 793-811. doi:10.5194/hess-13-793-2009

[9] M. H. T. Qari, "Geomorphology of Jeddah Governorate, with Emphasis on Drainage Systems," Journal of King Abdulaziz University: Earth Sciences, Vol. 20, No. 1, 2009, pp. 93-116.

[10] D. E. Raitsos, I. Hoteit, et al., "Abrupt Warming of the Red Sea," Geophysical Research Letters, Vol. 38, No. 5 2011, p. L14601.

[11] G. A. Grell, J. Dudhia and D. R. Stauffer, "A Description of the Fifth Generation Penn State/NCAR Mesoscale Model (MM5)," National Center for Atmospheric Research, Boulder, 1994.

[12] J. Thiébaux, E. Rogers, W. Wang and B. Katz, "A New High-Resolution Blended Real-Time Global Sea Surface Temperature Analysis," BAMs, Vol. 84, No. 5, 2003, pp. 645-656.

[13] S. Y. Hong and H. L. Pan, "Nonlocal Boundary Layer Vertical Diffusion in a Medium-Range Forecast Model," Monthly Weather Review, Vol. 124, No. 10, 1996, pp. 
2322-2339.

[14] J. Dudhia, "A Multi-Layer Soil Temperature Model for MM5," Preprints, 6th Annual MM5 Users Workshop, Boulder, 1996.

[15] S. G. Benjamin, "Some Effects of Surface Heating and Topography on the Regional Severe Storm Environment," Ph.D. Thesis, Dept. of Meteorology, The Pennsylvania State University, University Park, 1983.

[16] J. Reisner, R. M. Rasmussen and R. T. Bruintjes, "Explicit Forecasting of Supercooled Liquid Water in Winter Storms Using the MM5 Mesoscale Model," Quarterly Journal of the Royal Meteorological Society, Vol. 124, No. 548, 1998, pp. 1071-1107.

[17] T. Dinku S. J. Connor and P. Ceccato, "Comparison of CMORPH and TRMM-3B42 over Mountainous Regions of Africa and South America," Springer Netherlands, Dordrecht, 2010. doi:10.1007/978-90-481-2915-7 11

[18] N. Islam and H. Uyeda, "Use of TRMM in Determining the Climatic Characteristics of Rainfall over Bangladesh," Remote Sensing of Environment, Vol. 108, No. 3, 2007, pp. 264-276. doi:10.1016/j.rse.2006.11.011

[19] K. Suprit and D. Shankar, "Resolving Orographic Rain- fall on the Indian West Coast," International Journal of Climatology, Vol. 28, No. 5, 2008, pp. 643-657. doi:10.1002/joc. 1566

[20] A. Yatagai and P. Xie, "Utilization of a Rain-GaugeBased Daily Precipitation Dataset over Asia for Validation of Precipitation Derived from TRMM/PR and JRA25," SPIE, pp. 6404-6453. doi:10.1117/12.723829

[21] J. P. Evans, "21st Century Climate Change in the Middle East," Climatic Change, Vol. 92, No. 3-4, 2009, pp. 417 432 ,

[22] J. P. Evans, "Global Warming Impact on the Dominant Precipitation Processes in the Middle East," Theoretical and Applied Climatology, Vol. 99, No. 3, 2010, pp. 389402.

[23] F. M. Al Zawad, "Impacts of Climate Change on Water Resources in Saudi Arabia," The 3rd International Conference on Water Resources and Arid Environments, Riyadh, 16-19 November, 2008, pp. 1-26

[24] X. Zhang, E. Aguilar, S. Sensoy, et al., "Trends in Middle East Climate Extreme Indices from 1950 to 2003," Journal of Geophysical Research, Vol. 110, No. D22, 2005, pp. D22104.1-D22104.12. doi:10.1029/2005JD006181 